\title{
Puerarin Suppresses Angiotensin II-Induced Cardiac Hypertrophy by Inhibiting NADPH Oxidase Activation and Oxidative Stress-Triggered AP-1 Signaling Pathways
}

\author{
Gang Chen ${ }^{1}$, Qiang $\mathrm{Cao}^{2}$, Xiangli Cui ${ }^{1}$, Shifen Pan $^{1}$, Chong Shen ${ }^{3}$, Lihong Liu ${ }^{1}$ \\ ${ }^{1}$ Beijing Chao-Yang Hospital, Capital Medical University, Beijing, China. ${ }^{2}$ Clinical College of Traditional Chinese \\ Medicine, Gansu University of Chinese Medicine, Lanzhou, China. ${ }^{3}$ Institute of Medicinal Biotechnology, Chinese \\ Academy of Medical Sciences \& Peking Union Medical College, Beijing, China.
}

Received, February 9, 2015; Revised, May 16, 2015, Accepted, May 16, 2015; Published, June 18, 2015.

\begin{abstract}
PURPOSE. To examine the effects of puerarin (Pue) on angiotensin II (AngII)-induced nicotinamide adenine dinucleotide phosphate (NADPH) oxidase activation and oxidative stress-related signaling pathways in the hypertrophic response of cardiomyocytes. METHODS. Primary cardiomyocytes of neonatal C57BL/6J mice were pretreated with Pue $(50,100 \mu \mathrm{mol} / \mathrm{L})$ and were then stimulated with AngII $1 \mu \mathrm{mol} / \mathrm{L}$. NADPH oxidase activity and reactive oxygen species (ROS) levels were measured by lucigenin-enhanced chemiluminescence assay and flow cytometry. Western blotting was used to detect the distribution of the oxidase subunits, extracellular signal-regulated kinase (ERK1/2) and c-jun N-terminal kinase (JNK1/2) activation, and an electrophoretic mobility shift assay (EMSA) was performed to analyze the DNA binding activity of activator protein-1 (AP-1). Adult C57BL/6J mice were infused with AngII and were administered with Pue $\left(100,200 \mathrm{mg} \cdot \mathrm{kg}^{-1} \cdot \mathrm{d}^{-1}\right)$ for $15 \mathrm{~d}$. After the treatment, systolic blood pressure (SBP) and left ventricular wall thickness were examined. The ratios of heart weight to body weight (HW/BW) and left ventricular weight to body weight (LVW/BW) were measured, and heart morphometry was assessed. RESULTS. In vitro, Pue dose-dependently blocked the phosphorylation of ERK1/2 and JNK1/2 and eventually abolished AP-1 binding activity through the inhibition of ROS production. Further studies revealed that AngII treatment resulted in increased NADPH oxidase activity, which was suppressed by Pue via the disruption of Rac1 activation and membrane translocation of oxidase subunits. In vivo, Pue attenuated cardiac hypertrophy, as evaluated by decreased HW/BW, LVW/BW, myocyte surface area, and left ventricular wall thickness. CONCLUSIONS. The anti-hypertrophic mechanism of Pue occurred by blocking Rac1-dependent NADPH oxidase activation and downstream redox-sensitive AP-1 signaling pathways.
\end{abstract}

This article is open to POST-PUBLICATION REVIEW. Registered readers (see "For Readers") may comment by clicking on ABSTRACT on the issue's contents page.

\section{INTRODCTION}

Cardiac hypertrophy is characterized by a period of compensatory cardiac growth, which consists of increases in the size and mass of the heart, followed eventually by a transition to heart failure (1). Accumulating evidence has indicated that hypertrophic growth of the myocardium develops against the background of an activated renin-angiotensin system, and increased generation of reactive oxygen species (ROS) is involved in this pathological process. Angiotensin II (AngII), a bioactive peptide contributing to cardiac hypertrophy, activates nicotinamide adenine dinucleotide phosphate (NADPH) oxidase, leading to increased production of ROS, such as hydrogen peroxide, superoxide anions, and hydroxyl radicals (2). To date, NADPH oxidase has been considered a major source of ROS, corresponding to the effects of AngII on cardiovascular tissues, and NADPH oxidase is a critical determinant of the redox state of the myocardium (3, 4). Moreover, many of the downstream events triggered by AngII have been found to be redox-sensitive, such as MAPK family members, PI3Ka-Akt, Jak-STATs, AMP-activated protein kinase, and DNA-binding transcription factors, including NF- $\mathrm{KB}$, activator protein-1 (AP-1), etc. $(5,6)$.

Correspondence Author: Lihong Liu, Pharmacy Department of Beijing Chao-Yang Hospital, 8 Gongren Tiyuchang Nanlu, Chaoyang District, Beijing, China. E-mail: chengang102009@126.com. 
Therefore, these findings have suggested that inhibition of AngII-induced NADPH oxidase activation might be an effective approach to the manipulation of cardiac hypertrophy.

Puerarin

(Pue; 7 , 4'-dihydroxy-8- $\beta$-D-glucosylisoflavone, $\mathrm{C}_{21} \mathrm{H}_{20} \mathrm{C}_{9}$ ) is a bioactive isoflavone glucoside derived from the traditional Chinese medicine Radix puerariniae (7). In China, Pue has shown comprehensive pharmacological actions for the clinical treatment of cardiovascular diseases, such as coronary artery disease, heart failure (8), hypertension (9), and arrhythmia (10). The reported pharmacological actions of Pue on cardiovascular diseases are that it improves microcirculation; that it inhibits cardiac calcium influx, cardiac internal flow of $\mathrm{Na}^{+}$, and inward rectifier potassium channels; and that the cardioprotective effects of Pue are associated with its antioxidant and antilipid peroxidation properties and with a reduction in transforming growth factor- $\beta_{1}$ expression through the activation of the peroxisome proliferator-activated receptor $\alpha / \gamma$ (11). However, little information is available concerning the possible impact of Pue on $\mathrm{NADPH}$ oxidase activation or regarding the intracellular distribution of its subunits in cardiomyocytes after AngII induction. In the present study, our results first indicated that Pue attenuated c-jun N-terminal kinase (JNK1/2), extracellular signal-regulated kinase (ERK1/2) activation and AP-1 binding activity due to the inhibitory effects on Rac1-dependent NADPH oxidase activation and the resulting oxidative stress. Our findings could provide novel insights into the mechanisms underlying the beneficial effects of Pue on cardiovascular diseases.

\section{MATERIALS AND METHODS}

\section{Materials}

Dulbecco's modified Eagle's medium/F12 medium (DMEM/F12) and fetal bovine serum (FBS) were purchased from Hyclone (Waltham, MA, USA). Cardiac-specific anti-sarcomeric $\alpha$-actinin antibody, Pue, N-acetylcysteine (NAC), apocynin, PD98059, bromodeoxyuridine (BrdU), and AngII were bought from Sigma-Aldrich (St. Louis, MO, USA). 2, 7-dichlorodihydrofluorescein diacetate $\left(\mathrm{H}_{2}\right.$ DCFDA) and TRIzol were obtained from Invitrogen (Carlsbad, CA, USA). SP600125 was purchased from Calbiochem (San Diego, CA, USA). NSC23766 was purchased from Millipore
(Billerica, MA, USA). Anti-phospho-specific ERK1/2, anti-phospho-specific JNK1/2, anti-ERK1/2, and anti-JNK1/2 antibodies were obtained from Cell Signaling Technology (Danvers, MA, USA). Anti-c-jun, anti-c-fos, anti-HistoneH1, anti-GAPDH, anti- $\mathrm{Na}^{+} / \mathrm{K}^{+}$-ATPase, anti-p47phox, and anti-p67phox antibodies were purchased from Santa Cruz Biotechnology (Dallas, TX, USA). All of the other reagents used in this study were of an analytical grade.

\section{Neonatal mouse primary cardiomyocyte culture}

All of the experiments with animals were approved by the Animal Ethical and Welfare Committee of Chinese Academy of Medical Sciences \& Peking Union Medical College, and all of the animal experiments conformed to the Guide to the Care and Use of Experimental Animal Care (Canadian Council on Animal Care guidelines, 1984).

Ventricular cardiomyocytes were isolated from 1- to 2-day-old neonatal C57BL/6J mice (Vital River Laboratories, Beijing, China) as described previously, with minor modifications (12). In brief, minced ventricular myocardium was dissolved in a solution of $0.125 \%$ trypsin without EDTA. After each of several successive 5-min incubations, the dissociated cells were mixed with DMEM/F12 containing $12.5 \%$ FBS, and they were centrifuged and pooled. The dissociated cells were enriched for cardiomyocytes by differential adhesion for $60 \mathrm{~min}$ and were plated at a density of $1.0 \times 10^{5}$ cells $/ \mathrm{cm}^{2}$. The cultures were incubated in a humidified environment of $5 \% \mathrm{CO}_{2}-95 \% \mathrm{O}_{2}$ at $37{ }^{\circ} \mathrm{C}$. BrdU was added at a concentration of $100 \mu \mathrm{mol} / \mathrm{L}$ to the medium to inhibit the proliferation of non-myocytes. This procedure yielded cultures with $95 \%$-98 \% myocytes, as identified by anti-sarcomeric, $\alpha$-actinin, FITC immunohistochemistry. After 3 nights of incubation in DMEM/F12 containing $12.5 \%$ FBS, the attached cells were grown to $90 \%$ confluence and then were maintained in DMEM/F12 containing $0.1 \% \mathrm{FBS}$. After $24 \mathrm{~h}$ of serum starvation, the cardiomyocytes were pretreated for $2 \mathrm{~h}$ with 50 or $100 \mu \mathrm{mol} / \mathrm{L}$ Pue, 10 $\mathrm{mmol} / \mathrm{L}$ NAC, $10 \mu \mathrm{mol} / \mathrm{L}$ apocynin, $10 \mu \mathrm{mol} / \mathrm{L}$ PD98059, $20 \mu \mathrm{mol} / \mathrm{L}$ SP600125 or $20 \mu \mathrm{mol} / \mathrm{L}$ NSC23766 and were then stimulated with or without $1 \mu \mathrm{mol} / \mathrm{L}$ AngII for the indicated times. The cells were then harvested and extracted for the analysis. Pue was dissolved in dimethyl 
sulfoxide (DMSO). This stock solution was diluted to the final concentrations with the extracellular solution before application. The final concentration of DMSO did not exceed $0.1 \%$, and no effects of the vehicle were found in our experiments.

\section{Cytotoxicity assay}

The cells were cultured in 96-well plates at a density of $8 \times 10^{3}$ cells/well for $24 \mathrm{~h}$ and then were incubated with different concentrations of Pue for $48 \quad$ h. Next, $5 \quad \mu \mathrm{L}$ of 3-(4,5-dimethylthiazol-2-yl)-2,5-diphenyltetrazoli um bromide (MTT) at a concentration of 5 $\mathrm{mg} / \mathrm{mL}$ was added to each well and was incubated for $4 \mathrm{~h}$ at $37^{\circ} \mathrm{C}$. After removing the MTT medium, $200 \mu \mathrm{L}$ of DMSO were added. The plates were then read using an enzyme-linked immunosorbent assay plate reader (Bio-Rad, Hercules, CA, USA) at $570 \mathrm{~nm}$. The viability of the cells was assayed based on the optical density (OD) value.

\section{Detection of in vitro and in vivo ROS production}

The determination of intracellular ROS production was based on the oxidation of $\mathrm{H}_{2}$ DCFDA into fluorescent 2, 7-dichlorofluorescein (DCF). For the in vitro analysis, the cells were loaded with a solution of 5 $\mu \mathrm{mol} / \mathrm{L} \mathrm{H}_{2} \mathrm{DCFDA}$ for $30 \mathrm{~min}$ at $37^{\circ} \mathrm{C}$ in the dark. The cells were treated with AngII in the presence or in the absence of Pue for the indicated times. The cells were subsequently washed twice with phosphate-buffered saline (PBS), detached by trypsin, harvested and then immediately analyzed with a BD FACSCalibur (BD Biosciences, San Diego, CA, USA) cytometer, with excitation and emission settings of $488 \mathrm{~nm}$ and $530 \mathrm{~nm}$, respectively. For each sample, 10000 cells were counted. For the in vivo analysis, as previously described (13), $300 \mathrm{mg}$ of ventricle tissue were homogenized with a homogenizer for $20 \mathrm{~s}$ in 2 $\mathrm{mL}$ of a hypotonic lysis buffer containing 10 $\mathrm{mmol} / \mathrm{L} \quad \mathrm{KCl}, 2 \mathrm{mmol} / \mathrm{L} \quad \mathrm{MgCl}_{2}, \quad 1 \mathrm{mmol} / \mathrm{L}$ dithiothreitol (DTT), $0.1 \mathrm{mmol} / \mathrm{L}$ EDTA, 0.1 $\mathrm{mmol} / \mathrm{L}$ phenylmethylsulfonyl fluoride (PMSF), 1 $\mu \mathrm{mol} / \mathrm{L}$ pepstatin, $2 \mu \mathrm{mol} / \mathrm{L}$ leupeptin, $20 \mathrm{mmol} / \mathrm{L}$ $\beta$-glycerophosphate, $20 \mathrm{mmol} / \mathrm{L} \mathrm{NaF}, 2 \mathrm{mmol} / \mathrm{L}$ $\mathrm{Na}_{3} \mathrm{VO}_{4}$, and $10 \mathrm{mmol} / \mathrm{L}$ hydroxyethyl piperazine ethane-sulfonic acid (HEPES), at a $\mathrm{pH}$ of 7.4. $\mathrm{H}_{2}$ DCFDA at a concentration of $25 \mu \mathrm{mol} / \mathrm{L}$ was added to the homogenates to yield a final volume to $250 \mu \mathrm{L}$. Changes in fluorescence intensity were measured every $5 \mathrm{~min}$ for $30 \mathrm{~min}$ on a GENios fluorescence plate reader (Tecan Instruments, Salzburg, Austria), with excitation and emission wavelengths set at 485 and $530 \mathrm{~nm}$, respectively.

\section{Measurements of NADPH oxidase activity in vitro and in vivo}

NADPH oxidase activity was determined using an assay based on the lucigenin-enhanced chemiluminescence assay, as described previously (14). Briefly, for the in vitro analysis, the cells were centrifuged at $1000 \times \mathrm{g}$ for $5 \mathrm{~min}$ at $4{ }^{\circ} \mathrm{C}$. The pellet was resuspended in lysis buffer containing $20 \mathrm{mmol} / \mathrm{L}$ monobasic potassium phosphate $(\mathrm{pH}$ 7.0), $1 \mathrm{mmol} / \mathrm{L}$ ethylene glycol tetraacetic acid (EGTA), $10 \mu \mathrm{g} / \mathrm{mL}$ aprotinin, $0.5 \mu \mathrm{g} / \mathrm{mL}$ leupeptin, $0.7 \mu \mathrm{g} / \mathrm{mL}$ pepstatin, and $0.5 \mathrm{mmol} / \mathrm{L}$ PMSF. The cell suspension was stored on ice until use. For the in vivo analysis, tissues samples were gently homogenized using a dounce homogenizer in ice-cold buffer containing $10 \mathrm{mmol} / \mathrm{L}$ HEPES $(\mathrm{pH}$ 7.4), $0.5 \mathrm{mmol} / \mathrm{L} \mathrm{MgCl}_{2}, 10 \mathrm{mmol} / \mathrm{L} \mathrm{KCl}, 0.1$ $\mathrm{mmol} / \mathrm{L}$ EDTA, $0.1 \mathrm{mmol} / \mathrm{L}$ EGTA, $50 \mathrm{mmol} / \mathrm{L}$ $\mathrm{NaF}, \quad 5 \mathrm{mmol} / \mathrm{L} \quad \mathrm{DTT}, \quad 10 \mathrm{mmol} / \mathrm{L}$ $\beta$-phosphoglycerol, $1 \mathrm{mmol} / \mathrm{L} \mathrm{Na} \mathrm{VO}_{4}, 1 \mathrm{mmol} / \mathrm{L}$ PMSF, $1 \mathrm{mmol} / \mathrm{L}$ 4-nitrophenyl phosphate and protease inhibitors. The cell suspension or homogenates were sonicated as total protein lysates. The protein content was measured using a Modified Lowry protein assay kit (Pierce, Rockford, IL, USA). NADPH oxidase activity was assessed by luminescence assay in 50 $\mathrm{mmol} / \mathrm{L}$ phosphate buffer $(\mathrm{pH}$ 7.0) containing 1 $\mathrm{mmol} / \mathrm{L}$ EGTA, $150 \mathrm{mmol} / \mathrm{L}$ sucrose, $5 \mu \mathrm{mol} / \mathrm{L}$ lucigenin as the electron acceptor, and 100 $\mu \mathrm{mol} / \mathrm{L}$ NADPH as the substrate. Enzyme reactions were initiated with the addition of NADPH. No enzymatic activity could be detected in the absence of NADPH. Photoemissions were measured over $10 \mathrm{~min}$ in quadruplicate with a Lumat LB9507 luminometer (Berthold Technologies GmbH \& Co. KG, Germany) in 1 min intervals. The results are expressed as relative light units (RLUs) per microgram of cell extract.

\section{Measurements of Rac1 activation}

Activated Rac1 was determined by p21-binding domain of p21-activated protein kinase 1 pull-down assay, according to the manufacturer's protocol for the Rac1 Activation Assay Kit (Cell Biolabs, San Diego, CA, USA).

Preparation of cell fraction extracts and western blot analysis

Plasma membrane, cytoplasmic, and nucleus 
protein enriched fractions were prepared using a Plasma Membrane Protein Extraction Kit and a Nuclear/Cytosol Fractionation Kit, according to the manufacturer's instructions (BioVision Inc., Milpitas, CA, USA).

After various treatments, the cardiomyocytes or ventricular tissue was lysed with lysis buffer containing $50 \mathrm{mmol} / \mathrm{L}$ Tris- $\mathrm{HCl}(\mathrm{pH} 7.5), 250$ $\mathrm{mmol} / \mathrm{L} \mathrm{NaCl}, 5 \mathrm{mmol} / \mathrm{L}$ EDTA, $50 \mathrm{mmol} / \mathrm{L} \mathrm{NaF}$, $1 \mathrm{mmol} / \mathrm{L}$ DTT, $1 \%$ TritonX-100, $1 \mathrm{mmol} / \mathrm{L}$ $\mathrm{Na}_{3} \mathrm{VO}_{4}$ and protease inhibitors. After centrifugation, the supernatant fraction was removed, and the protein concentrations were determined using the Bio-Rad protein assay. The proteins were separated by SDS-PAGE and were transferred onto a polyvinylidene fluoride membrane. After blocking with $5 \%$ nonfat milk blocking buffer (PBS containing $0.1 \%$ Tween20, $\mathrm{pH}$ 7.5), the membrane was incubated with the desired primary antibody overnight at $4{ }^{\circ} \mathrm{C}$ and then was incubated with an appropriate peroxidase-conjugated secondary antibody. The density of the immunoreactive bands was visualized using the ECL Plus Western Blotting Detection System (Piscataway, NJ, USA).

\section{Semi-quantitative RT-PCR assay}

Total RNA was isolated from the ventricular tissue or cardiomyocytes using TRIzol reagent, according to the manufacturer's instructions, and RT-PCR was then performed with the PrimeScript ${ }^{\mathrm{T}}$ RT reagent Kit (Takara, Dalian, China). The resulting cDNA was amplified by PCR for the fetal genes. The following primers (Invitrogen, Carlsbad, CA, USA) were used for the PCR: atrial natriuretic peptide (ANP): 5'-GTGTACAGTGCGGTGTCCAA-3' (sense) and 5'-ACCTCATCTTCTACCGGCATC-3' (anti-sense); brain natriuretic peptide (BNP): 5'-GAGGTCACTCCTATCCTCTGG-3' (sense) and 5'-GCCATTTCCTCCGACT TTTCT-3' (anti-sense); $\beta$-myosin heavy chain ( $\beta$-MHC): 5'-GCATTCTCCTGCTGTTTCC TT-3' (sense) and 5'-TGGATTCTCAAACGTGTCTAGTGA-3' (anti-sense); and GAPDH: 5'-CGGAGTCAACGGATTTGGTCGTAT-3' (sense) and 5'-AGCCTTCTCCATGGTGGTG AAGAC-3' (anti-sense). The conditions used for the PCR were as follows: $94{ }^{\circ} \mathrm{C}$ for $3 \mathrm{~min} ; 94{ }^{\circ} \mathrm{C}$ for $30 \mathrm{~s} ; 50{ }^{\circ} \mathrm{C}$ for $20 \mathrm{~s} ; 72^{\circ} \mathrm{C}$ for $20 \mathrm{~s}$; and $72{ }^{\circ} \mathrm{C}$ for $10 \mathrm{~min}$, for a total of 32 cycles.

\section{Electrophoretic mobility shift assay (EMSA)} EMSA was performed according to the manufacturer's instructions from the Gel Shift Assay System Commercial Kit (Promega, Madison, WI, USA). The AP-1 DNA-binding site oligonucleotides

5'-CGCTTGATGACTCAGCCGGAA-3' were 5' end labeled with $\mathrm{T}_{4}$ polynucleotide kinase and $\left[\gamma^{32} \mathrm{P}\right]$ ATP (Promega, Madison, WI, USA). Nuclear protein at a mass of $10 \mu \mathrm{g}$ was pre-incubated in a total volume of $9 \mu \mathrm{L}$ in a binding buffer, consisting of $10 \mathrm{mmol} / \mathrm{L}$ Tris- $\mathrm{HCl}$ (pH 7.5), $4 \%$ glycerol, $1 \mathrm{mmol} / \mathrm{L} \mathrm{MgCl}_{2}, 0.5$ $\mathrm{mmol} / \mathrm{L}$ EDTA, $0.5 \mathrm{mmol} / \mathrm{L}$ DTT, $0.5 \mathrm{mmol} / \mathrm{L}$ $\mathrm{NaCl}$, and $0.05 \mathrm{mg} / \mathrm{mL}$ poly (dI: $\mathrm{dC}$ ) for $10 \mathrm{~min}$ at room temperature. After the addition of the ${ }^{32} \mathrm{P}$-labeled oligonucleotide probe, the incubation was continued for $20 \mathrm{~min}$ at room temperature. The reaction was stopped by adding $1 \mu \mathrm{L}$ of gel-loading buffer, and the protein-DNA binding complexes were subjected to nondenaturing $4.8 \%$ polyacrylamide gel electrophoresis in $0.5 \times \mathrm{TBE}$ buffer $(44.5 \mathrm{mmol} / \mathrm{L}$ Tris, $44.5 \mathrm{mmol} / \mathrm{L}$ boric acid, and $1 \mathrm{mmol} / \mathrm{L}$ EDTA). After electrophoresis was conducted, the gel was vacuum-dried and exposed to X-ray film (Fuji Hyperfilm, Tokyo, Japan) at $-70{ }^{\circ} \mathrm{C}$ with an intensifying screen.

\section{Cardiomyocyte surface area assay}

Cardiomyocyte surface area was measured according to a previously described method (15). Cell images were captured with a digital camera fixed to a microscope (IX71-F22FL/PH, Olympus, Tokyo, Japan). The cardiomyocyte surface area was analyzed using Image Pro-Plus software, version 6.0, and a quantitative digital image analysis system (Media Cybernetics, Rockville, MD, USA). A total of 100 cells from randomly selected fields in 3 wells were examined for each condition. Cardiomyocyte surface area was determined after $48 \mathrm{~h}$ of treatment with AngII, Pue, and apocynin, compared with control cells.

\section{Measurement of $\left[{ }^{3} \mathbf{H}\right]$ leucine incorporation}

$\left[{ }^{3} \mathrm{H}\right]$ leucine incorporation was measured as described previously (16). Cells were grown in 24-well plates with serum-free medium for $24 \mathrm{~h}$. The cells were then treated with AngII for $24 \mathrm{~h}$ after pretreatment with or without puerarin or other inhibitors. The cells were pulsed with 1 $\mu \mathrm{Ci} / \mathrm{mL}$ of $\left[{ }^{3} \mathrm{H}\right]$ leucine (Amersham Biosciences, Piscataway, NJ, USA) during the last $4 \mathrm{~h}$ before harvest. After being washed with PBS, the cells were treated with $5 \%$ trichloroacetic acid for 30 min and then were washed with PBS again. Finally, the cells were solubilized in $500 \mu \mathrm{L}$ of 1 
$\mathrm{mol} / \mathrm{L} \mathrm{NaOH}$. After neutralization with $0.5 \mathrm{~mol} / \mathrm{L}$ $\mathrm{HCl}$, an aliquot was obtained to determine the level of incorporated radioactivity, using the Beckman LS 3801 liquid scintillation counter (Beckman, Fullerton, CA, USA).

\section{Modified Lowry method for protein content assay \\ Cardiomyocytes were cultured in a 12-well plate at density of $5.0 \times 10^{5}$ cells/well for $24 \mathrm{~h}$, and the total protein content per well was measured with a Modified Lowry protein assay kit (Pierce, Rockford, IL, USA).}

\section{Animals and protocols}

Eight-week-old, healthy, specific pathogen-free grade, male C57BL/6J mice weighing 19-21 g were purchased from Vital River Laboratories (SCXK jing 2014-0006, Beijing, China) and were randomly divided into 5 groups ( $\mathrm{n}=10 /$ group): (1) a sham group of vehicle-infused mice that received only PBS; (2) an AngII-infused group; (3) a Pue treatment group that received oral gavage administration of Pue at a dose of $100 \mathrm{mg} \cdot \mathrm{kg}^{-1} \cdot \mathrm{d}^{-1}$ dissolved in sterile water; (4) a Pue treatment group that received oral gavage administration of Pue at a dose of $200 \mathrm{mg} \cdot \mathrm{kg}^{-1} \cdot \mathrm{d}^{-1}$ dissolved in sterile water; and (5) an apocynin treatment group that received oral gavage administration of apocynin at a dose of $100 \mathrm{mg} \cdot \mathrm{kg}^{-1} \cdot \mathrm{d}^{-1}$ dissolved in sterile water. The dose of apocynin in the present study was chosen on the basis of a previous study (17). All of the groups except the sham group simultaneously received AngII $\left(2.5 \mu \mathrm{g} \cdot \mathrm{kg}^{-1} \cdot \mathrm{min}^{-1}\right.$, dissolved in PBS including $10 \mu \mathrm{mol} / \mathrm{L}$ acetic acid) by a subcutaneously implanted mini-pump (model 2002, Alza, Mountain View, CA, USA) for 15 d (18). Pue or apocynin was administered for 15 consecutive $\mathrm{d}$ after surgery. The mice were housed in temperature-controlled and humidity-controlled rooms under a $12 \mathrm{~h} \mathrm{light} / 12 \mathrm{~h}$ dark cycle. All of the mice had free access to feed and drinking water.

\section{Systolic blood pressure assessment and echocardiography}

After $15 \mathrm{~d}$ of treatment, echocardiography was performed using a Siemens Acuson CV-70 ultrasonographic system (Siemens Medical Solutions, Mountain View, CA, USA) as previously reported (19). Briefly, isoflurane $1.5 \%$ mixed with $\mathrm{O}_{2}$ was used to provide adequate sedation but minimal cardiac suppression during echocardiography, and the mice were placed in the supine position. A probe at $13 \mathrm{MHz}$ was applied to the left hemithorax. M-mode measurements of left ventricular end-diastolic diameter, end-systolic diameter and wall thickness were performed according to American Society of Echocardiography guidelines. The following parameters were obtained: left ventricular end diastolic diameter (LVEDD), left ventricular end systolic diameter (LVESD), left ventricular posterior wall thickness (LVPWth) and interventricular septal wall thickness (IVSth). Fractional shortening (FS) was calculated as (LVEDD-LVESD)/LVEDD $\times 100 \%$.

Systolic blood pressure (SBP) was measured twice per week after the implantation of the minipump, using the tail-cuff method without anesthesia as previously described (20). Briefly, the mice were placed in restraints, and their body temperature was maintained at $34{ }^{\circ} \mathrm{C}$ using a warming chamber. An IITC tail cuff sensor (IITC Life Science, Woodland Hills, CA, USA), containing both an inflation cuff and a photoelectric sensor, was placed on the tail and attached to the restrainer. The cuff was inflated to a pressure of $200 \mathrm{~mm} \mathrm{Hg}$ and then was deflated slowly. Upon the reappearance of pulse signals, SBP data from the IITC amplifier were recorded, analyzed and reported by the IITC Life Science Blood Pressure System software.

\section{Morphological examination}

After $15 \mathrm{~d}$ of treatment, the mice were weighed and euthanized. The heart was weighed after the blood vessels and all of the epicardial fat were removed. The ratios of heart weight to body weight (HW/BW) and left ventricular weight to body weight (LVW/BW) were calculated to use as indices of cardiac hypertrophy. The histopathological observation procedures were performed by the institute of Laboratory Animal Science, Chinese Academy of Medical Sciences \& Peking Union Medical College. Immediately after gross dissection, the left ventricles were sectioned into 2- to 3-mm-thick slices and were immersed in a formalin solution for more than $7 \mathrm{~d}$. The sections were then dehydrated in ethanol, cleared in dimethylbenzene and finally embedded in paraffin. The paraffin-embedded sections of the left ventricle were then cut into 5 - $\mu \mathrm{m}$-thick sections and were stained with hematoxylin-eosin (H\&E) for light microscopic evaluation. A single myocyte was measured with the Image Pro-Plus quantitative digital image analysis system, version 6.0. The outlines of 100 cardiomyocytes were 
traced in each group.

\section{STATISTICAL ANALYSIS}

The data are expressed as mean \pm SEM. Significant differences between groups were tested by one-way analysis of variance (ANOVA) with the Tukey's correction or with the unpaired t-test for continuous variables using SPSS statistical software (SPSS, Chicago, IL, USA), version 16.0. A two-tailed Student's t-test at $p$ value $<0.05$ was used to determine statistically significant.

\section{RESULTS}

In vitro measurements of ROS, NADPH oxidase activity and signaling proteins induced by AngII

AngII increased NADPH oxidase activity and intracellular ROS production in a time-dependent manner $(\mathrm{P}<0.01)$ (Figure $1 \mathrm{~A}$ and $1 \mathrm{~B})$. ERK1/2, JNK1/2, and AP-1 have been noted as important regulators of the hypertrophic response (21).
Western blot analysis showed that AngII time-dependently upregulated the phosphorylated levels of ERK1/2 and JNK1/2, the nuclear expression of c-jun, c-fos, and AP-1 binding activity $(\mathrm{P}<0.01)$ (Figure $1 \mathrm{C}$ and $1 \mathrm{D})$. The optimal responses were achieved at $4 \mathrm{~h}$, and the cells were therefore stimulated with AngII for $4 \mathrm{~h}$ in subsequent experiments.

\section{Effects of Pue on cell viability}

Exposure of cultured cardiomyocytes to Pue for $48 \mathrm{~h}$ did not have any significant effects on cardiomyocyte viability (Figure 1E).

The in vitro effects of Pue on the intracellular production of ROS and NADPH oxidase activation

AngII triggered an increase in ROS levels and NADPH oxidase activity, which were decreased by Pue in a dose-dependent manner, similar to the inhibitory effects observed with NSC23766, apocynin or NAC $(\mathrm{P}<0.05$ or $\mathrm{P}<0.01)$ (Figure $2 \mathrm{~A}$ and $2 \mathrm{~B})$.


B

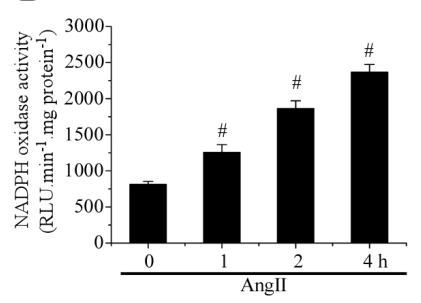



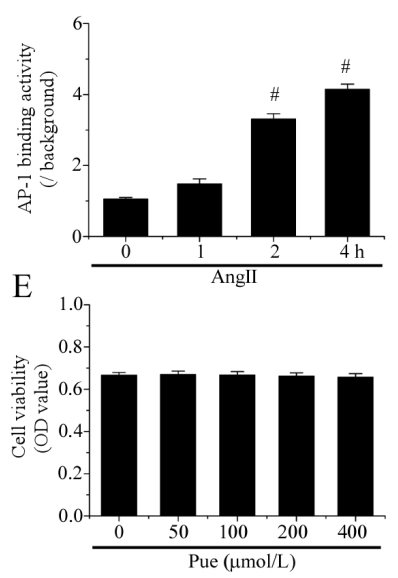



Figure 1. Measurements of ROS production, NADPH oxidase activity, and the activation of signaling proteins induced by AngII in vitro. (A) AngII time-dependently increased the levels of ROS. (B) AngII time-dependently induced NADPH oxidase activation. (C) AngII time-dependently up-regulated the phosphorylated levels of ERK1/2 and JNK1/2 and the nuclear expression of c-jun and c-fos. (D) AngII time-dependently increased AP-1 binding activity. (E) Effects of Pue on the viability of cardiomyocytes. Histone H1 was used to confirm an equal amount of nuclear protein loading for each sample. Mean $\pm \mathrm{SEM}, \mathrm{n}=4$. ${ }^{\#} p<0.01$ vs the control group. 

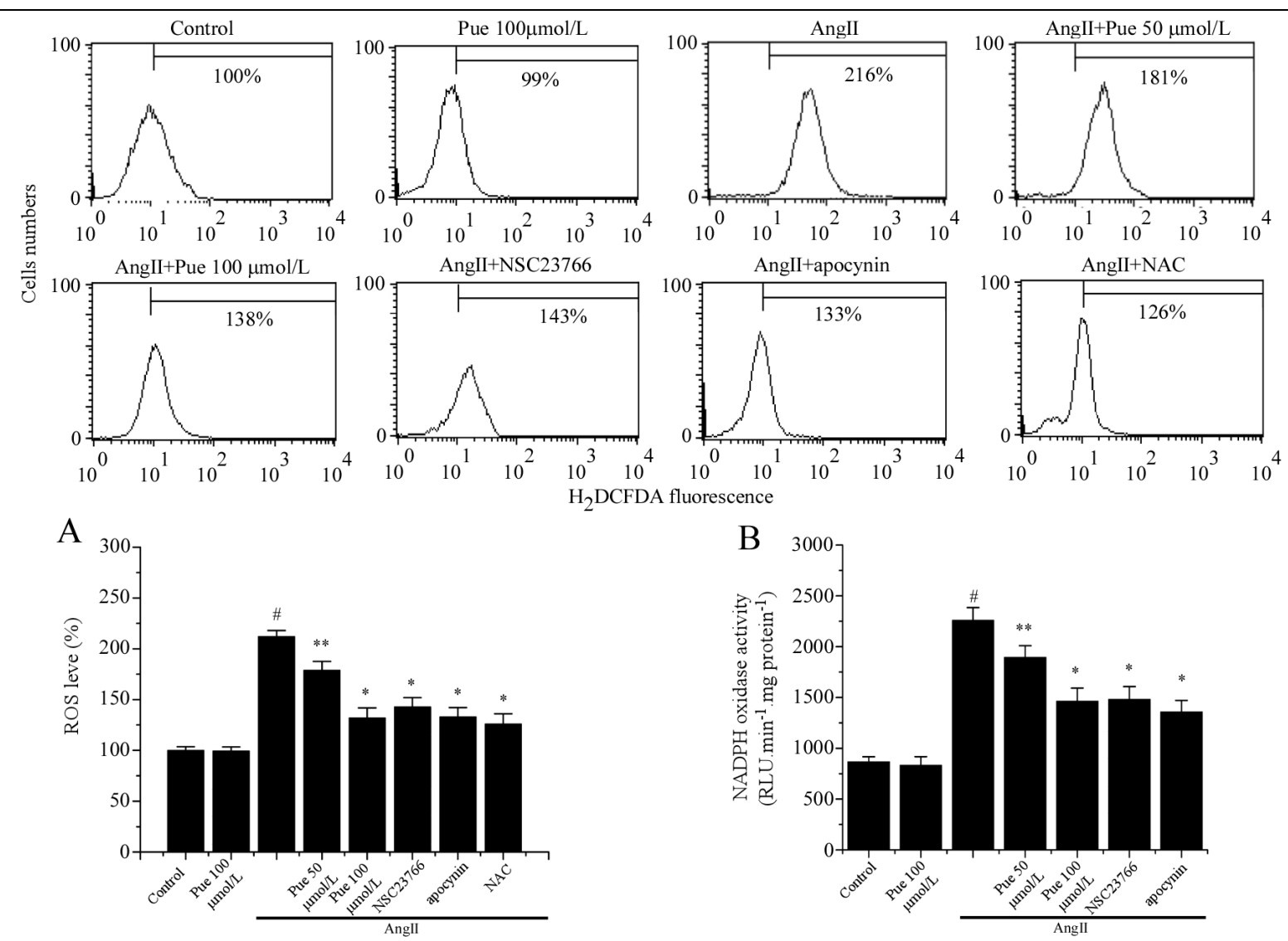

Figure 2. Effects of Pue on AngII-induced intracellular ROS generation and NADPH oxidase activity in vitro. (A) Pue dose-dependently inhibited intracellular production of ROS. (B) Pue dose-dependently inhibited NADPH oxidase activity. Mean $\pm \mathrm{SEM}, \mathrm{n}=4 .{ }^{*} p<0.01$ vs the control group, ${ }^{*} p<0.01$ vs the AngII-treated group, ${ }^{* *} p<0.05$ vs the AngII-treated group.

\section{Effects of Pue on NADPH oxidase subunit assembly}

To investigate the mechanisms by which Pue inhibited ROS production and NADPH oxidase activation, we examined the effects of Pue on NADPH oxidase subunits. NADPH oxidase is composed of cytosolic subunits, including Rac1, $\mathrm{p} 47^{\text {phox }}$, and $\mathrm{p} 67^{\text {phox }}$. Upon activation, the NADPH oxidase subunits translocated from the cytosol to the plasma membrane, stimulating enzymatic activity and triggering the production of ROS (22). In our experiment, AngII induced a marked increase in the levels of active Rac1 and plasma membrane translocation of Rac1, p4 $7^{\text {phox }}$, and p6 $67^{\text {phox }}$ in a time-dependent manner $(\mathrm{P}<0.01)$ (Figure 3A). However, Pue treatment blocked Rac1 activation and membrane translocation of the oxidase subunits in a dose-dependent manner. Similarly, the inhibitory effects on these oxidase subunits were also observed by NSC23766, a Rac1-specific blocker $(\mathrm{P}<0.05$ or $\mathrm{P}<0.01)$ (Figure 3B).
Blockade of ERK1/2 and JNK1/2 and AP-1 pathway activation by Pue

To measure whether ERK1/2, JNK1/2, and AP-1 activation was associated with upstream intracellular ROS generation and NADPH oxidase activation, cultured cardiomyocytes were respectively pretreated with Pue, NSC23766, apocynin or NAC for $2 \mathrm{~h}$ and then were stimulated by AngII. Pue treatment dose-dependently inhibited the marked AngII-induced increase in the phosphorylated levels of ERK1/2 and JNK1/2 and nuclear expression of c-jun and c-fos, and the activation of these processes was suppressed by NSC23766, apocynin or NAC $(\mathrm{P}<0.05$ or $\mathrm{P}<0.01)$ (Figure 4A). Moreover, the results of EMSA confirmed that Pue could dose-dependently inhibit AP-1 binding activity, and inhibitory effects were also observed by treatment with NSC23766, apocynin, PD98059 or SP600125, respectively $(\mathrm{P}<0.05$ or $\mathrm{P}<0.01$ ) (Figure 4B). 

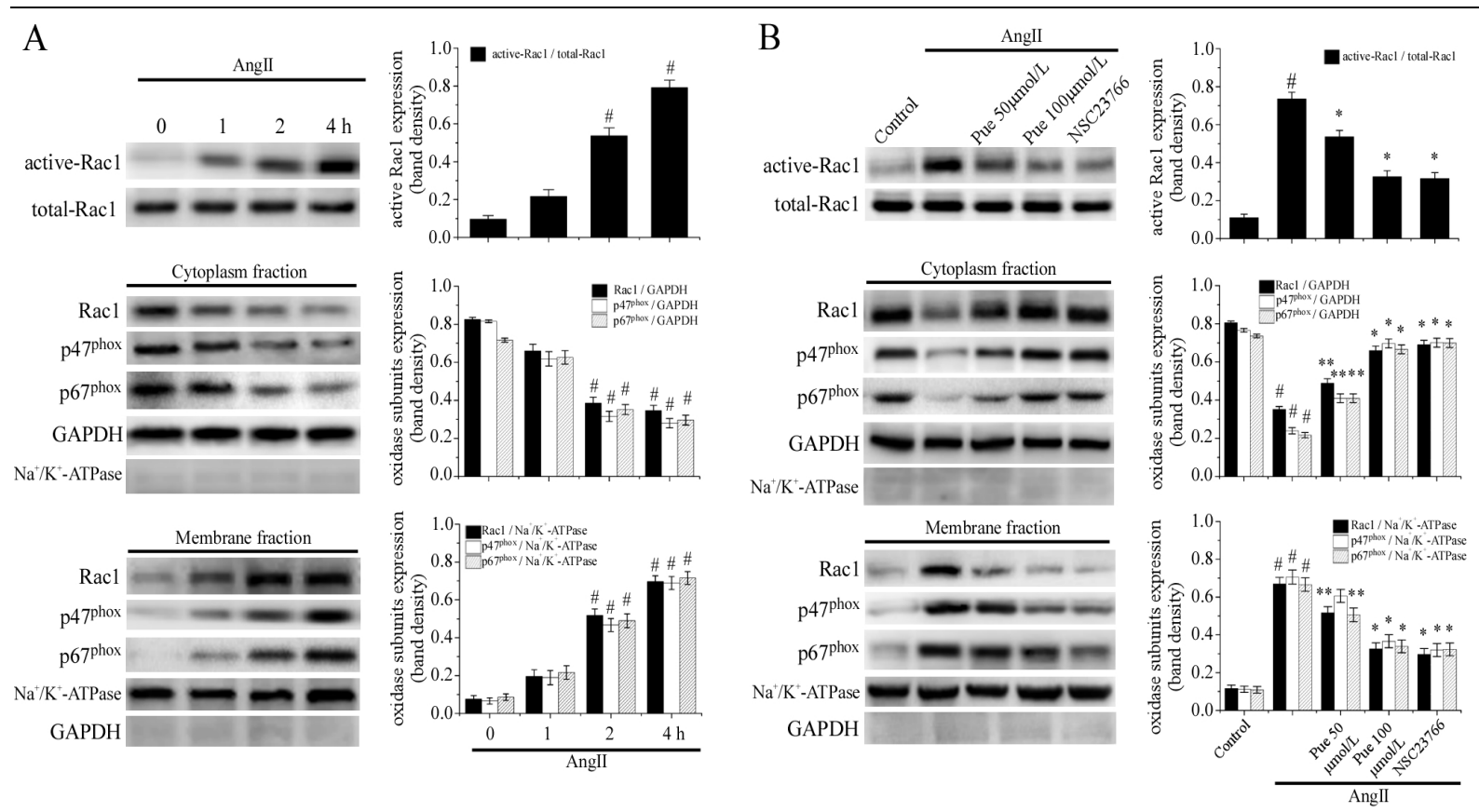

Figure 3. Effects of Pue on AngII-induced NADPH oxidase subunits distribution. (A) AngII time-dependently induced Rac1 activation and membrane translocation of Rac1, p47phox, and p67phox. (B) Pue dose-dependently disrupted Rac1 activation and the membrane translocation of Rac1, p47phox , and p67phox. GAPDH and $\mathrm{Na}^{+} / \mathrm{K}^{+}$-ATPase were used to confirm an equal amount of cytoplasmic and membrane protein loading for each sample, respectively. Mean $\pm \mathrm{SEM}$, $\mathrm{n}=4$. ${ }^{*} p<0.01$ vs the control group, ${ }^{*} p<0.01$ vs the AngII-treated group, ${ }^{* *} p<0.05$ vs the AngII-treated group.

A



B



Figure 4. Effects of Pue on AngII-induced ERK1/2 and JNK1/2 activation and AP-1 binding activity. (A) Pue dose-dependently suppressed AngII-induced phosphorylation of ERK1/2 and JNK1/2 and nuclear expression of c-jun and c-fos. (B) Pue dose-dependently attenuated AngII-induced AP-1 DNA binding activity. Histone H1 was used to confirm an equal amount of nuclear protein loading for each sample. Mean \pm SEM, $\mathrm{n}=4$. ${ }^{\#} p<0.01$ vs the control group, ${ }^{*} p<0.01$ vs the AngII-treated group, ${ }^{* *} p<0.05$ vs the AngII-treated group. 


\section{Effects of Pue on AngII-induced cultured} cardiomyocyte hypertrophy

Cardiomyocyte hypertrophy is characterized by the expression of fetal-type genes and increases in protein synthesis and cell size. We therefore examined the effects of Pue on these parameters. Cardiomyocytes were pretreated with Pue 100 $\mu \mathrm{mol} / \mathrm{L}$ for $2 \mathrm{~h}$ before stimulation with AngII. Pue suppressed the AngII-induced expression of the ANP and $\beta$-MHC genes for $24 \mathrm{~h}(\mathrm{P}<0.01)$ (Figure 5A). Moreover, the increases in $\left[{ }^{3} \mathrm{H}\right]$ leucine incorporation and total protein content detected after $24 \mathrm{~h}$ of culture in the presence of AngII were prevented in the cells preincubated with Pue $(\mathrm{P}<0.01)$ (Figure $5 \mathrm{~B})$. Furthermore, the hypertrophic response was determined after $48 \mathrm{~h}$. AngII induced a marked increase in cell surface area, which was inhibited by Pue $(\mathrm{P}<0.01)$ (Figure 5C). In addition, apocynin, SP600125, and PD98059 were employed to determine whether the inhibition of AngII-induced cardiomyocyte hypertrophy by Pue occurred via the attenuation of NADPH oxidase-related ROS formation and by the activation of the downstream JNK1/2, ERK $1 / 2$ or AP-1 pathways. The results indicated that apocynin, SP600125, and PD98059 could markedly reduce the AngII-induced protein synthesis and fetal-type gene mRNA expression in the cardiomyocytes $(\mathrm{P}<0.01)$.

\section{Pue attenuates cardiac hypertrophy in vivo}

After $15 \mathrm{~d}$ of experimentation, the percentage of animals with cardiac hypertrophy was $98.3 \%$, as evidenced by increases in the cardiomyocyte surface area and HW/BW and LVW/BW ratios, compared with the sham group. In either Pue- or apocynin-treated mice, the AngII-induced increases in cardiomyocyte surface area and the HW/BW and LVW/BW ratios were markedly attenuated by long-term treatment with Pue or apocynin $(\mathrm{P}<0.01)$ (Figure 6A). The results of M-model echocardiography showed that treatment with Pue or apocynin prevented both the decreases in LVESD and LVEDD and the increases in IVSth, LVPWth and FS that were observed in the group infused with AngII alone (P $<0.01$ ) (Figure 6B). The SBP was significantly higher in the AngII-infused mice than in the sham mice during AngII perfusion, and this increase in SBP was markedly decreased with Pue or apocynin treatment $(\mathrm{P}<0.01)$ (Figure 7A).
A
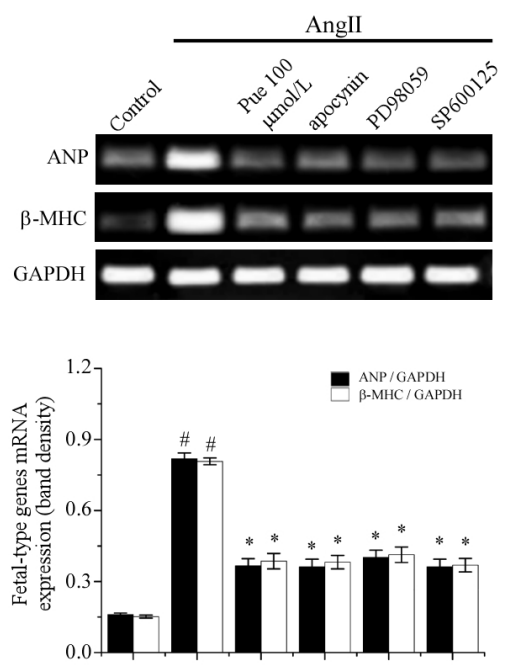

B
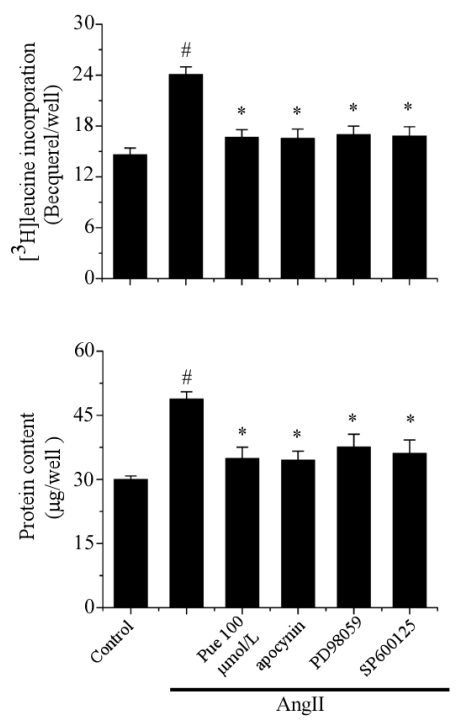

$\mathrm{C}$



Figure 5. Effects of Pue on AngII-induced hypertrophic response in cultured cardiomyocytes. (A) Pue inhibited AngII-induced expression of fetal-type genes in the cardiomyocytes. (B) The bar graph shows that Pue inhibited the rate of protein synthesis and the total protein content induced by AngII in the cardiomyocytes. (C) Representative images of cultured cardiomyocytes (original magnification $\times 400$ ). The bar graph shows that Pue decreased AngII-increased cardiomyocyte surface area. Mean \pm SEM, $\mathrm{n}=4$. \# $p<0.01$ vs the control group, ${ }^{*} p<0.01$ vs the AngII-treated group. 


\section{Effects of Pue on redox-sensitive signaling} molecules in vivo

To examine whether our in vitro findings for signaling molecules had physiological relevance, we measured the effects of Pue on ROS production, NADPH oxidase activity, and redox-sensitive signaling molecules in vivo. Semi-quantitative RT-PCR analysis was performed to determine the effects of Pue on the mRNA expression levels of ANP, BNP, and $\beta$-MHC genes in vivo. The results revealed a marked attenuation of the observed increase in expression levels in the AngII-infused group when these animals were treated with Pue or apocynin $(\mathrm{P}<0.01)$ (Figure $7 \mathrm{~B})$. In agreement with the in vitro findings, in vivo infusion of AngII triggered an increase in ROS levels, NADPH oxidase activity, phosphorylated levels

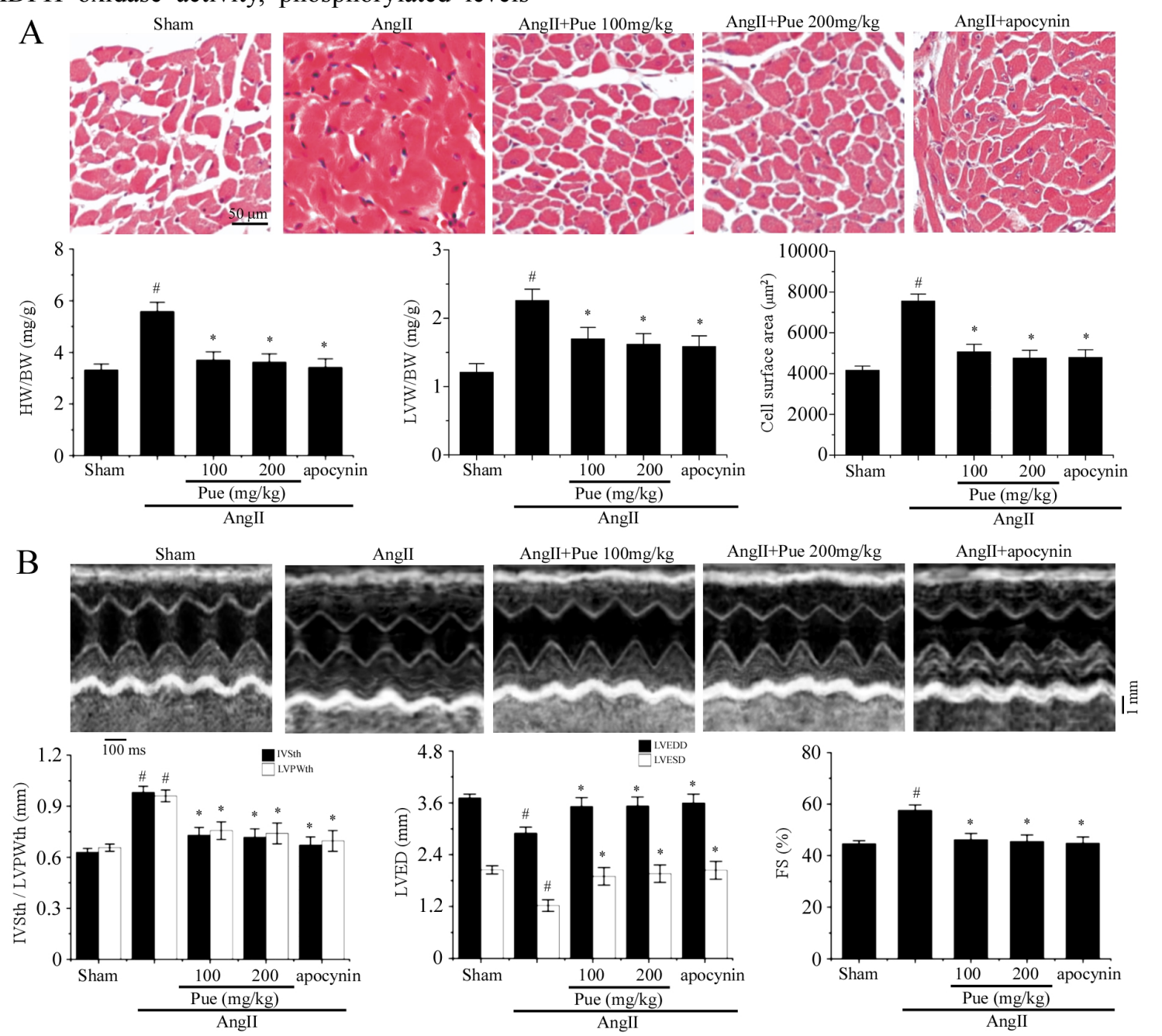

Figure 6. The in vivo inhibitory effect of Pue on cardiac hypertrophy. (A) Representative cross-sections of the left ventricles stained with $\mathrm{H} \& \mathrm{E}$ (original magnification $\times 200$ ); Bar graph shows the quantitative analysis of $\mathrm{HW} / \mathrm{BW}$, LVW/BW, and mean cell area. (B) Representative M-mode images of cardiac hypertrophy assessed by echocardiography after $15 \mathrm{~d}$ of AngII infusion; bar graph shows the quantitative analysis of IVSth, LVPWth, LVED, and FS \%. Mean $\pm \mathrm{SEM}, \mathrm{n}=4 .{ }^{\#} p<0.01$ vs the control group, ${ }^{*} p<0.01$ vs the AngII-treated group. of ERK1/2 and JNK1/2, and AP-1 DNA binding activity, which were decreased by Pue or apocynin $(\mathrm{P}<0.01)$ (Figure 7C-7F).

\section{DISCUSSION}

The aims of this study were to examine the inhibitory effects of Pue on oxidative stress-triggered cardiomyocyte hypertrophy in response to AngII stimulation and to elucidate their underlying mechanisms. We observed from following results. In cultured cardiomyocytes, Pue suppressed marked AngII-induced increases in cell size, re-expression of fetal-type genes, and protein synthesis. In animal experiments, we used AngII infused by mini-pump to establish cardiac hypertrophy. 



Figure 7. Effects of Pue on increases in SBP during AngII perfusion in mice and on ROS production, signaling protein activation, and re-expression of fetal-type genes in the left ventricles. (A) Pue suppressed AngII-induced increases in SBP. (B) Pue inhibited AngII-induced re-expression of fetal-type genes. (C) Pue reduced AngII-induced ROS production. (D) Pue inhibited AngII-induced NADPH oxidase activation. (E) Pue inhibited AngII-induced phosphorylation of ERK1/2 and JNK1/2. (F) Pue attenuated AngII-induced DNA binding activity of AP-1. The left ventricles were randomly chosen from each group. Mean $\pm \mathrm{SEM}, \mathrm{n}=4$. ${ }^{*} p<0.01$ vs the control group, ${ }^{*} p<0.01$ vs the AngII-treated group.

After long-term induction, the characteristic hypertrophic changes, such as increases in $\mathrm{HW} / \mathrm{BW}$ ratios and LVW/BW ratios, enlarged sizes of cardiomyocytes, greater chamber sizes and wall thicknesses, and the recapitulation of fetal isoforms of cardiac genes, were markedly inhibited by long-term treatment with 100 or 200 $\mathrm{mg} \cdot \mathrm{kg}^{-1} \cdot \mathrm{d}^{-1}$ Pue or $100 \mathrm{mg} \cdot \mathrm{kg}^{-1} \cdot \mathrm{d}^{-1}$ apocynin. Then, we attempted to investigate the molecular mechanisms by which Pue inhibited cardiac hypertrophy. We detected AngII-enhanced phosphorylation of ERK1/2 and JNK1/2 and nuclear expression of c-jun and c-fos, as well as AP-1 binding activity in a time-dependent manner, which was blocked by Pue, NSC23766 or apocynin. A growing body of evidence has shown that ROS acts as a second messenger during ventricular remodeling in response to AngII, and its downstream redox-regulated signal pathways includes ERK1/2, JNK1/2, AP-1, etc. (23). Additionally, we observed that the phosphorylated levels of ERK1/2 and JNK1/2 were directly upregulated by exogenous $\mathrm{H}_{2} \mathrm{O}_{2}$ in our experiments (data not shown). Therefore, the explanation of the inhibitory effects of Pue on these signaling pathways activation might be its potential to influence intracellular ROS generation.

AngII is a well-known powerful inducer of oxidative stress in cardiovascular tissues, and the main enzyme source for the production of ROS in AngII-treated cells is derived from NADPH oxidase. In cardiomyocytes, NADPH oxidase comprises a membrane-integrated cytochrome $\mathrm{b}_{558}$ composed of gp9 $91^{\text {phox }}$ and $\mathrm{p} 22^{\text {phox }}$, which is regulated by several cytosolic regulatory subunits, 
including $\mathrm{p} 47^{\text {phox }}, \mathrm{p} 67^{\text {phox }}, \mathrm{p} 40^{\text {phox }}$, and the small G-protein Rac1. Upon stimulation, the activation of NADPH oxidase was required for the cytosolic subunits to assemble with the membrane subunits to form a functioning oxidase that evoked $\mathrm{NADPH}$ oxidase activity and subsequently an oxidative burst $(24,25)$. An important step in NADPH oxidase assembly is interaction among p67 $7^{\text {phox }}$, active GTP-bound Rac1, and gp91 phox Rac1 is required to anchor cytosolic p67phox to the membrane and to promote an "active form" of $\mathrm{p} 67^{\text {phox }}$. Inhibition of Rac1 leads to diminished Rac1-p67phox complex formation and prevents membrane translocation of $\mathrm{p} 47^{\text {phox }}$ and $\mathrm{p} 67^{\text {phox }}$, eventually resulting in diminished activation of NADPH oxidase $(26,27)$. Our results showed that following AngII stimulation, intracellular ROS production time-dependently increased, and these effects were abolished in a dose-dependent manner not only by Pue but also by treatment with apocynin, a specific NADPH oxidase inhibitor, or NSC23766, a specific Rac1 inhibitor, suggesting that AngII mediates the generation of ROS through NADPH oxidase, as well as Rac1 activation. In western blot analysis, we found that AngII promoted Rac1 activation and membrane translocation of Rac1, p $47^{\text {phox }}$, and $\mathrm{p} 67^{\text {phox }}$ in a time-dependent manner, which was dose-dependently disrupted by Pue. Moreover, NSC23766 could block the effects of AngII on the membrane translocation of $\mathrm{p} 47^{\text {phox }}$ and $\mathrm{p} 67^{\text {phox }}$, indicating that translocation of both $\mathrm{p} 47^{\mathrm{phox}}$ and p6 $67^{\text {phox }}$ is dependent on Rac1 activation, in agreement with previous findings (27-29). Therefore, the prevention of AngII-induced Rac1 activation by Pue might be responsible for its inhibitory effects on the membrane translocation of $\mathrm{p} 47^{\text {phox }}$ and $\mathrm{p} 67^{\text {phox }}$ subunits and subsequent $\mathrm{NADPH}$ oxidase activation, as well as ROS production. There have been studies reporting that, in vascular smooth muscle cells and retinal pericytes, high-glucose or glycation products activated Rac1 through phosphorylation serine residue, and Pue blocked NADPH oxidase activation through Rac1 dephosphorylation (28, 29). Whether the inhibitory effects of Pue on Rac1 activation in AngII-treated cardiomyocytes was associated with the phosphorylation status of Rac1 or with other upstream elements remains to be further determined. Early mediators of hypertrophic transcriptional programming include the transient activation of immediate-early genes, such as c-jun and c-fos, which create the heterodimer complex called AP-1 (30). AP-1 is ubiquitously expressed, and it controls various genes involved in apoptosis, cell survival and growth, all of which are involved in myocardial hypertrophy (31). The expression and nuclear accumulation of AP-1 serve as indicators of downstream gene activation $(32,33)$, and it has been well established that JNK1/2 and ERK1/2 are involved in the activation of AP-1 by regulating the expression and stabilization of c-Jun and c-fos proteins $(34,35)$. Hence, sequent experiments were performed to analyze the effects of Pue on the nuclear protein expression of the two major components of the AP-1 complex: c-fos and c-jun. The present study, using western blot, provided evidence that nuclear distribution of c-fos and c-jun was significantly increased in cardiomyocytes exposed to AngII, and these increases were respectively abrogated by Pue, NSC23766, apocynin, PD98059 or SP600125. The following gel-shift assays showed that AP-1 DNA binding activity was also markedly attenuated by the same drugs. These studies suggested that decreased AP-1 binding activity resulted from decreases in c-fos and c-jun protein levels through the inhibition of redox-sensitive ERK1/2 and JNK1/2. Thus, it is not surprising that Pue interfered with NADPH oxidase-derived ROS formation, and associated downstream AP-1 signaling pathways were also blocked.

\section{CONCLUSION}

Taken together, the present study provided important new insights into the molecular mechanisms of the effects of Pue on cardiomyocyte hypertrophy. These data suggested for the first time that Pue attenuates cardiac hypertrophy by inhibiting Rac1-dependent NADPH oxidase activation and then blocking the downstream redox-sensitive AP-1 signaling pathways.

\section{ACKNOWLEGEMENTS}

The work was supported by grants from the National S\&T Major Special Project on Major New Drug Innovation (2012ZX09301002-001-015) and National Scientific Foundation of China (30772284).

\section{REFERENCES}

1. De Leeuw PW, Kroon AA. Hypertension and the development of heart failure. J Cardiovasc 
Pharmacol. 1998; 32: 9-15. review.

2. Nakagami H, Takemoto M, Liao JK. NADPH oxidase-derived superoxide anion mediates angiotensinII-induced cardiac hypertroph. J Mol Cell Cardiol. 2003; 35: 851-859.

3. Williams HC, Griendling KK. NADPH oxidase inhibitors: new antihypertensive agents? J Cardiovasc Pharmacol. 2007; 50: 9-16.

4. Bendall JK, Cave AC, Heymes C, Gall N, Shah AM. Pivotal role of a gp91(phox)-containing $\mathrm{NAD}(\mathrm{P}) \mathrm{H}$ oxidase in AngII-induced cardiac hypertrophy in mice. Circulation. 2002; 105: 293-296.

5. Frank GD, Eguchi S, Yamakawa T, Tanaka S, Inagami T, Motley ED. Involvement of reactive oxygen species in the activation of tyrosine kinase and extracellular signal-regulated kinase by AngII. Endocrinology. 2000; 141: 3120-3126.

6. Garrido AM, Griendling KK. NADPH oxidases and AngII receptor signaling. Mol Cell Endocrinol. 2009; 302: 148-158.

7. Zhang Z, Lam TN, Zuo Z. Radix puerariniae: An overview of Its Chemistry, Pharmacology, Pharmacokinetics, and Clinical Use. J Clin Pharmacol. 2013; 53: 787-811.

8. Feng ZQ, Wang YY, Guo ZR, et al. The synthesis of puerarin derivatives and their protective effect on the myocardial ischemia and reperfusion injury. J Asian Nat Prod Res. 2010; 12: 843-850.

9. Song XP, Chen PP, Chai XS. Effects of puerarin on blood pressure and plasma renin activity in spontaneously hypertensive rats. Zhongguo Yao Li Xue Bao. 1988; 9: 55-58.

10. Zhang $\mathrm{H}$, Zhang L, Zhang Q, et al. puerarin: a novel antagonist to inward rectifier potassium channel (ik1). Mol Cell Biochem. 2011; 352: 117-123.

11. Zhou YX, Zhang H, Peng C. puerarin: a review of pharmacological effects. Phytother Res. 2014; 28 : 961-975.

12. Fei AH, Cao Q, Chen SY, Wang HR, Wang FL, Pan SM, et al. Salvianolate inhibits reactive oxygen species production in $\mathrm{H}_{2} \mathrm{O}_{2}$-treated mouse cardiomyocytes in vitro via the TGF $\beta$ pathway. Acta Pharmacol Sin. 2013; 34: 496-500.

13. Kim JM, Heo HS, Ha YM, Ye BH, Lee EK, Choi YJ, et al. Mechanism of Ang II involvement in activation of NF- $\kappa$ B through phosphorylation of p65 during aging. AGE. 2012; 34: 11-25.

14. Zhang QG, Raz L, Wang R, Han D, De Sevilla L, Yang F, Vadlamudi RK, Brann DW. Estrogen attenuates ischemic oxidative damage via an estrogen receptor alpha-mediated inhibition of NADPH oxidase activation. J Neurosci. 2009; 29:
13823-13836.

15. Zou XJ, Yang L, Yao SL. Propofol depresses angiotensinII-induced cardiomyocyte hypertrophy in vitro. Exp Biol Med. 2011; 2008; 233: 200-208.

16. Nakamura K, Fushimi K, Kouchi H, Mihara K, Miyazaki M, Ohe T. Inhibitory effects of antioxidants on neonatal rat cardiac myocyte hypertrophy induced by tumor necrosis factor alpha and angiotensinII. Circulation. 1998; 98: 794-799.

17. Yu-qiong LI, Xiao-bo LI, Shu-jie GUO, Shao-li CHU, Ping-jin GAO, Ding-liang ZHU, Wen-quan NIU, Nan JIA. Apocynin attenuates oxidative stress and cardiac fibrosis in AngII-induced cardiac diastolic dysfunction in mice. Acta Pharmacologica Sin. 2013; 34: 352-359.

18. Dai WJ, Chen HY, Jiang JD, Kong WJ, Wang YG. Silencing MR-1 attenuatesinflammatory damage in mice heart induced by AngII. Biochem Biophys Res Commun. 2010; 391: 1573-1578.

19. Shiomi T, Tsutsui H, Ikeuchi M, Matsusaka H, Hayashidani S, Suematsu N, et al. Streptozotocin-induced hyperglycemia exacerbates left ventricular remodeling and failure after experimental myocardial infarction. J Am Coll Cardiol. 2003; 42: 165-172.

20. Whitesall SE, Hoff JB, Vollmer AP, D’Alecy LG. Comparison of simultaneous measurement of mouse systolic arterial blood pressure by radiotelemetry and tail-cuff methods. Am J Physiol. 2004; 286: H2408-2415.

21. Tu VC, Bahl JJ, Chen QM. Distinct roles of p42/p44 (ERK) and p38MAPK in oxidant-induced AP-1 activation and cardiomyocyte hypertrophy. Cardiovasc Toxicol. 2003; 3: 119-133.

22. Seshiah PN, Weber DS, Rocic P, Valppu L, Taniyama Y, Griendling KK. AngiotensinII stimulation of $\mathrm{NAD}(\mathrm{P}) \mathrm{H}$ oxidase activity: upstream mediators. Circ Res. 2002; 91: 406-413.

23. Izumi Y1, Kim S, Zhan Y, Namba M, Yasumoto H, Iwao H. Important role of angiotensinII-mediated c-Jun $\mathrm{NH}(2)$-terminal kinase activation in cardiac hypertrophy in hypertensive rats. Hypertension. 2000; 36: 511-516.

24. Ferri N, Contini A, Bernini SK, Corsini A. Role of small GTPase protein Rac1 in cardiovascular diseases: development of new selective pharmacological inhibitors. J Cardiovasc Pharmacol. 2013; 62: 425-435.

25. Hordijk PL. Regulation of NADPH oxidases: the role of Rac proteins. Circ Res. 2006; 98: 453-462.

26. Carrizzo A, Forte M, Lembo M, Formisano L, Puca AA, Vecchione C. Rac-1 as a new therapeutic target in cerebro- and cardio-vascular 
diseases. Curr Drug Targets. 2014; 15: 1231-1246.

27. Satoh M, Ogita H, Takeshita K, Mukai Y, Kwiatkowski DJ, Liao JK. Requirement of Rac1 in the development of cardiac hypertrophy. Proc Natl Acad Sci USA. 2006; 103:7432-7437.

28. Zhu LH, Wang L, Wang D, Jiang H, Tang QZ, Yan L, Bian ZY, Wang XA, Li H. Puerarin attenuates high-glucose-and diabetes-induced vascular smooth musclecell proliferation by blocking PKC $\beta 2 /$ Rac1-dependent signaling. Free Radic Biol Med. 2010; 48: 471-482.

29. Kim J, Kim KM, Kim CS, Sohn E, Lee YM, Jo K, Kim JS. Puerarin inhibits the retinal pericyte apoptosis induced by advanced glycation end products in vitro and in vivo by inhibiting NADPH oxidase-related oxidative stress. Free Radic Biol Med. 2012; 53: 357-365.

30. Yano M, Kim S, Izumi Y, Yamanaka S, Iwao H. Differential activation of cardiac c-jun amino-terminal kinase and extracellular signal-regulated kinase in angiotensinII -mediated hypertension. Circ Res. 1998; 83: 752-760.

31. Wu S, Gao J, Ohlemeyer C, Roos D, Niessen H, Köttgen E, Gessner R. Activation of AP-1 through reactive oxygen species by angiotensinII in rat cardiomyocytes. Free Radic Biol Med. 2005; 39: 1601-1610.

32. Chatterjee N, Zou C, Osterman JC, Gupta NK: Cloning and characterization of the promoter region of a gene encoding a $67-\mathrm{kDa}$ glycoprotein. J Biol Chem. 1997; 272: 12692-12698.

33. Yan L, Zhang JD, Wang B, Lv YJ, Jiang H, Liu GL, Qiao Y, Ren M, Guo XF. Quercetin inhibits left ventricular hypertrophy in spontaneously hypertensive rats and inhibits angiotensinII-induced $\mathrm{H} 9 \mathrm{C} 2$ cells hypertrophy by enhancing PPAR- $\gamma$ expression and suppressing AP-1 activity. PLoS One. 2013; 8: 1-14.

34. Hilfiker-Kleiner D1, Hilfiker A, Castellazzi M, Wollert KC, Trautwein C, Schunkert H, Drexler H. JunD attenuates phenylephrine-mediated cardiomyocyte hypertrophy by negatively regulating AP-1 transcriptional activity. Cardiovasc Res. 2006; 71: 108-125.

35. Bing-Ying Ho, Yao-Ming Wu, King-Jen Chang, Tzu-Ming Pan. Dimerumic Acid Inhibits SW620 Cell Invasion by Attenuating H2O2-Mediated MMP-7 Expression via JNK/C-Jun and ERK/C-Fos Activation in an AP-1-Dependent Manner. Int. J. Biol. Sci. 2011; 7: 869-880. 